Max-Planck-Institut für demografische Forschung

Max Planck Institute for Demographic Research

Konrad-Zuse-Strasse 1 - D-18057 Rostock - GERMANY

Tel +49 (0) 3812081 - 0; Fax +49 (0) 3812081 - 202;

http://www.demogr.mpg.de

MPIDR WORKING PAPER WP 2009-037

NOVEMBER 2009

\title{
The impact of the individual, the household and the community on fertility behavior in Petén, Guatemala
}

Kathryn Grace (grace@demogr.mpg.de)

David Carr

This working paper has been approved for release by: Michaela Kreyenfeld (kreyenfeld@demogr.mpg.de), Acting Deputy Head of the Laboratory of Economic and Social Demography.

(C) Copyright is held by the authors.

Working papers of the Max Planck Institute for Demographic Research receive only limited review. Views or opinions expressed in working papers are attributable to the authors and do not necessarily reflect those of the Institute. 


\title{
The impact of the individual, the household and the community on fertility behavior in Petén, Guatemala
}

\author{
Kathryn Grace \\ Max Plank Institute for Demographic Research
}

David Carr

Department of Geography

University of California, Santa Barbara 


\begin{abstract}
This research explores fertility correlates in the Petén, a high fertility region of Guatemala, during the 1998-99 time period. By taking into account land use and labor characteristics at the household and community levels in addition to individual level factors related to the cost/benefit of children this research aims to update the traditional application of the demand framework used to examine fertility. Data from the 1998/99 Demographic and Health Survey containing a unique environmental module was used in concert with 2002 Population and Agricultural census data. The model was fit using a count variable (total children ever born) as the response. The results of the analysis highlight the significance of individual land use variables even after adjusting for socio-economic status and ethnicity.
\end{abstract}

\title{
1 Introduction
}

Recent demographic research has focused largely on the rapid decline of fertility rates throughout the developed and developing world. Substantial empirical research now buttresses classic theories of fertility decline and transition determinants. However, many questions about the mechanisms involved in maintaining high fertility rates or in catalyzing a decline among high fertility populations remain unanswered. While research inspired by the quick and unanticipated decline in birth rates can provide valuable insight into the demographic transition, it is imperative that population science maintain a commitment to empirical research of high fertility populations. Besides being the fastest growing populations, high fertility groups also tend to be those who suffer from the most extreme poverty, malnutrition, and dearth of health care and education. Concomitantly, they tend to live in rural remote regions which are increasingly situated in and around the world's ecological "hot spots" on which they have a considerable impact given that they are nearly all farmers and depend on the forest for felling in order to open agricultural fields and for fuel-wood (Carr 2008). Some researchers theorize that rural families deliberately produce more children because of their need for more agricultural and household labor (Caldwell \& Caldwell 1987, Lee 2001, Lee \& Kramer 2002, Carr, Pan \& Bilsborrow 2006). 
While some theories suggest that high fertility may be beneficial to farm families, the impact of different land-use strategies or agricultural practices is unknown. Hence, given similar access to contraception, economic theories of fertility suggest that agriculturalists would prefer (and achieve) greater family sizes than those engaged in less labor-intensive occupations. Do rural families who are engaged in labor-intensive agriculture have greater fertility than those who are mainly pastoral (cattle ranchers) or engaged in less labor intensive agriculture, after controlling for traditional determinants of fertility? In general, agriculture is more labor-intensive than cattle-raising and agriculturalists on marginal land with few technological implements have the greater labor demands (Carr et al. 2006). The limited related research has indicated that the land/fertility relationship is complex and fails to provide a definitive response to this conundrum. This study seeks to address this question using data from Petén, Guatemala, the Guatemalan sub-population characterized by the highest regional total fertility rate (TFR) in the country (see Figure 1, (MSPAS 2002)) and, at the time, the highest TFR of the Central American region. In fact, with a TFR exceeding 6, the level of fertility in Petén exceeds levels recorded for the majority of developing countries.

\section{Theories of Fertility Decline}

Do classic theories of fertility determinants apply to the rural agricultural frontier? According to Coale's (1973) three "preconditions" of fertility decline fertility decisions must be conscious decisions, contraception or "techniques of fertility reduction" must be accessible (intellectually as well as geographically), and the value of reducing one's fertility must be apparent (Coale 1973, Cleland \& Wilson 1987). Changes in factors affecting these preconditions can therefore be attributed to general cultural changes, changes in access to information and technology, and changes to the relative 'worth' and 'cost' of children. According to Cleland and Wilson (1987), the majority of fertility research has been directed towards the third listed precondition of fertility decline; the economics (cost/benefit) of childbirth and childrearing. Approaching fertility decline as an economic benefit to families and individuals has led the development 
and wide-spread use of the 'demand theory' of reproduction targeting the economics behind family planning decisions (Cleland \& Wilson 1987). In the agricultural frontier land use and household production strategies are important components of household income and labor needs. Therefore, based on Coale's preconditions, changes in the level of childbearing may be impacted by different land use patterns or labor needs.

The 'diffusion of innovations' theory or 'ideation' theory approach links the first two of Coale's preconditions and was developed as an explanation of fertility decline among Englishspeaking populations (Raftery, Lewis \& Aghajanian 1995). This decline, particularly notable in European countries with more than one national language, highlighted the similar pace and direction of fertility change among English speakers while non-English speakers followed a alternate transitional pathway. Coale and Watkins (1986), ultimately determined that the fertility transition therefore resulted from shared information regarding reproductive health technology as well as cultural and lifestyle ideals rather than from changes in socioeconomic factors (Raftery et al. 1995, Coale \& Watkins 1986).

\subsection{Direct and Indirect Determinants}

While the classic theories of decline offer a theoretical framework for analysis, the theories of direct and indirect determinants provide the guidelines for application and interpretation of the general theories. Incorporating direct and indirect determinants into the process of independent variable selection and interpretation of results is influenced by the work of Davis and Blake in the 1950s and the subsequent work of John Bongaarts in the 1970s. These authors established a heuristic for researching fertility determinants. According to this approach, direct fertility determinants are defined as a "set of biological and behavioral variables that directly affect reproductive behavior" (Knodel, Chamratrithirong \& Debavalya 1987, Davis \& Blake 1956, Bongaarts 1978). These factors are largely known as the proximate determinants of fertility. Bongaarts' proximate determinants: marital patterns, induced abortion, postpartum non-susceptibility, and contraception account for the majority of the worldwide variation in 
fertility (Martine 1996). Simply, fertility decline is predicated upon a change in one or more of these determinants (Cleland \& Wilson 1987). These classic proximate determinants theories are tested here in variable selection, and model interpretion in the context of a remote rural agricultural frontier characterized by very high fertility.

The individual in context: Incorporating contextual level variables allows the analyst to more accurately model real-world phenomena as women and families are impacted by and impact their surrounding community. Related research exploring health and lifestyle choices among women and families in Guatemala has begun to incorporate context variables with traditional individual variables (Pebley, Goldman \& Rodriguez 1996, Lindstrom \& MunozFranco 2005). Building on the idea that family size decisions may be influenced by community attitudes and motivations, it is preferable to incorporate contextual (in this case context refers specifically to municipality) information in addition to individual level information. Therefore, municipality level variables are included as proxy for social/cultural contexts while individual factors target individual decision-making. The following subsections posit broad theoretical categorizations and explanations for the selection and use of proximate independent variables.

Land-Fertility Hypothesis: Easterlin advanced the development of the supply/demand framework for analyzing reproductive decisions when, using a primarily economic perspective, he explored the fertility experience in the fairly homogeneous US 19th century frontier. In this setting, consistent with Coale's supply/demand precondition, he determined that fertility behavior is influenced initially by "tastes, prices, and income" and is subsequently affected by "infant and child mortality conditions" (i.e., compensatory births to accommodate high mortality and to reach the optimal family size) (Easterlin 1971). These ideas led to the development of a more specific component of the supply/demand framework, the land-fertility hypothesis. The implication of this hypothesis is that as long as children provide labor then the desire for large family size remains unchanged given that fertility is a conscious choice, largely impacted by the need of additional labor in the fields or in the home. Consonant with this theory, in the US 19th century westward frontier, more rural areas with more available land produced more children whereas the urban communities generally produced fewer children. 
More recent evidence of land-fertility interactions have framed the relationship between fertility and landholdings in three ways; 1) fertility increases in direct response to labor needs which are greater when more land is owned- land needs drive family size goals (Carr et al. 2006, Coomes, Grimad \& Diaz n.d., Binswanger \& McIntire 1987, Chayanov 1986, Clay \& Johnson 1992); 2) More land is sought to meet the needs of a growing family - family size drives land needs (Carr et al. 2006, Binswanger \& McIntire 1987, Chayanov 1986); and 3) Larger land-holdings may be indicative of higher socio-economic status correlated with the increased likelihood of infant and child survival - land holdings serve as a proxy for socioeconomic status which in some cases leads to reduced mortality and therefore higher fertility (Clay \& Johnson 1992). These positive land-fertility correlations have been documented in other developing country settings (Stokes, Schutjer \& Bulatao 1986, Cain 1984). However, as noted by Carr et al. (2006), the majority of related land-fertility research is conducted in settled agriculture areas. Therefore the relationship between land and fertility in this context, where land is abundantly available and where the majority of the population are rural dwellers, is unclear.

Although the use of cross-sectional survey data in this case limits our ability to determine causal relationships between land and fertility, we can measure the strength and direction of the relationship of fertility with labor demand. Dichotomous variables identifying sons as labor providers on the farm (in the survey the question is, "Do sons work in the fields?"), the ability of the household/farm to produce enough to sustain family consumption needs (in the survey the question is, "Is household production sufficient?"), and cattle ownership are included in the analysis. Following the previous land-fertility research, sons as labor is anticipated to be positively correlated with fertility as it measures a direct benefit of children to the family/farm. The second variable, household production, serves as an index both of farm size/production and time spent on the land, as well as addressing the potential need for more labor to increase production if currently insufficient. The final variable, cattle ownership, is a proxy for labor demand. Households who invest in cattle, which are less labor intensive than crops, are anticipated to have fewer children. The husband's or partner's (hereafter referred 
to as partner) education is also included to control for socio-economic status. Lastly, infant mortality, a dichotomous variable indicating whether the family has experienced the loss of one or more children, is included as a control variable.

Beyond the household characteristics, municipality land use characteristics may have an impact on individual fertility. Where more land is available, in this case usually unused forest land, families may feel more comfortable choosing to have more children. The percent of forested land per municipality is included to measure this relationship. The percentage of tractors per farm (count of tractors/count of farms) is included as a municipal level variable. Tractors are generally owned by only very wealthy landowners who are able to contract local labor. Besides selling crops, the only other viable strategy for impoverished families to increase household income is by contracting out husbands and sons to these more wealthy landowners.

Ideation: In fertility and social science research, theories of diffusion are used to explain the movement of ideas (Kohler, Behrman \& Watkins 2001). Social learning and social influence are highlighted as the two primary components of the diffusion of information process (Lindstrom \& Munoz-Franco 2005, Kohler et al. 2001, Montgomery \& Casterline 1996). Social learning is the process of obtaining information about new technologies and their effects from friends, family or community members either resulting from direct interactions or from information passed over mass-media (Kohler et al. 2001, Lindstrom \& Munoz-Franco 2005). Social influence reflects the idea that values can be transferred because of an individual's membership within a group and that personal preferences (i.e., contraceptive use and family size) may be influenced by group preferences (Kohler et al. 2001, Lindstrom \& Munoz-Franco 2005). Montgomery and Casterline (1996) identified increased awareness and knowledge of consequences, as well as pressure to conform, as three different effects of diffusion on fertility behaviors. In the case of rural Guatemala diffusion will likely occur differently than in urban communities since diverse community interactions are more limited and mass media influences may be less present. Diffusion, in general, however, has been shown to increase contraceptive knowledge in a variety of settings where variations in contraceptive use have more or less impact on individual behavior depending on the density of the social networks (Montgomery \& Casterline 1996, Entwisle, 
Rindfuss, Guilkey, Chamratrithirong, Curran \& Sawangdee 1996, Kohler et al. 2001). Identifying the characteristics of the diffusion of information in the rural and urban settings is an important component in understanding the effects of structural variation on fertility behavior. Additionally, understanding the process of diffusion of knowledge in a community facilitates effective and possibly community customized family planning policy (Kohler et al. 2001).

Incorporating ideas from diffusion theory in the Guatemalan setting is particularly important because of the tendency of Indigenous populations to be suspicious of the motives of "outsiders" who provide family planning information (Santiso-Galvez \& Bertrand 2004, Seiber \& Bertrand 2002, Bertrand, Seiber \& Escudero 2001). Clearly, in the case of Indigenous populations, information gained from individuals linked by strong social ties may be vitally important in an individual's understanding of family planning technology. In terms of variable selection and evaluating community characteristics, the theory of diffusion and its relationship to fertility change and transition suggests the importance of developing a solid understanding of the movements of ideas within a community and among neighboring communities and further developing an understanding of this process as it relates to development and population density. If individuals live in an urban environment they are expected to have fewer children as their exposure to family planning technologies should be greater than individuals who have lived only in rural settings.

Lindstrom and Munoz-Franco (2005) have shown that families and communities with outmigrants to urban or international locations have higher contraceptive use suggesting that information and values from these outside communities are seeping into relatively geographically isolated communities - reflecting this theory. To test this theory we have included a municipality-level variable measuring proportion of domestic out-migrants.

Socio-Demographic: Woman's age will be used to control for exposure to childbearing with the expectation that as women age the number of children they have increases. Younger women may also be more inclined to explore new fertility regulation techniques and therefore more likely to use contraception whereas older women may have reached their fertility goals and rely on fertility stopping techniques. A consistently important factor in the economic theory 
of fertility decline is the role of education. As education becomes more of a social norm more children therefore attend school and cannot contribute as "labor" to the family and their cost increases while their benefit decreases. The role of education can also represent a change in the community's values as well as those of the family or individual. For example, in an analysis of fertility decline in Iran, the role of education was examined from two different perspectives; the role of maternal education and the current acceptance and accessibility of education for children (Raftery et al. 1995).

As Guatemala's population is divided by ethnicity and language, we anticipate that the application of the proximate determinants will require different variable specification according to ethnic group. Ultimately this differentiation by ethnicity incorporates the different development, economic, and fertility pathways present in the diverse populations. Related research examining health and fertility outcomes within Guatemala has highlighted the necessity of exploring the ethnic differences in determinants and correlates of these outcomes (Seiber \& Bertrand 2002, Pebley, Goldman \& Robles 2005, Lindstrom 2003, Lindstrom \& MunozFranco 2005, De Broe \& Hinde 2006). The gap in living standards and contraceptive use among these populations suggests that different factors may well be resulting in similar reproductive health outcomes. Therefore, a dichotomous variable measuring ethnicity - Indigenous or Ladino - will be included in the analysis as a control variable (Pebley et al. 1996).

The variables used in the analysis are listed in Table 2. They were selected based on their impact on fertility as outlined in the previous section. They are further categorized into socio-demographic, land use and labor variables and identified as municipality level measures.

\section{Setting}

Guatemala's population is roughly equally divided ethnically (50\% Indigenous and 50\% Ladino (mixed ancestry) descent) and during the latter half of the 20th century suffered a turbulent civil war characterized by extreme violence directed towards the Indigenous community (Lovell 1999). Guatemala's rates of contraceptive use trail other Central American countries while 
its fertility rate is one of the highest in the region (Bertrand, de Salazar, Mazariegos, Salanic, Rice \& Sow 1999, Bertrand et al. 2001, De Broe \& Hinde 2006). Indeed, in rural areas of Guatemala the TFR exceeds 6 births per woman while in rural regions of the Petén, the region containing the Guatemalan frontier and the focus of this paper, completed fertility averages near 8 births per woman (Grandia \& Schwartz 2001), a level that approaches the observed limits for any world region at any time in world history and places Petén within the "belt of high fertility" that defines much of Northern Guatemala and the Highlands (De Broe \& Hinde 2006). Although aggregate Guatemalan fertility rates and lack of contraceptive use, as mentioned earlier, are unusually high for Latin America, the $6 \%$ contraception use rate among rural Mayas is extraordinarily low (compared to $50 \%$ of Ladinos) and may explain some of the differences in fertility outcomes between the two ethnic groups (Bertrand et al. 2001, De Broe \& Hinde 2006). Currently, the gap between Indigenous and Ladino fertility is increasing as the Ladino population has begun showing strong signs of fertility decline while the Indigenous population shows limited or no signs of decrease (De Broe \& Hinde 2006). Moreover, as the majority of Indigenous women live in rural settings, the fertility differences between Indigenous and Ladino populations are further impacted by the characteristic differences in fertility behavior between rural and urban communities.

In addition to unusually high fertility, this region is also characterized by severe loss of forest cover (Carr 2008). In fact, if deforestation rates return to the levels of the 1990s, within the next 10 years forests will no longer exist in Petén (Carr 2008). In response to concerns over land use change, several national parks protecting the delicate and unique rain-forests and Maya heritage sites, also found in this area, have been developed. Despite the preservation intentions, as land pressures push marginalized farmers out of other areas of the country the 'free' land of the national parks draws these impoverished families who eventually form communities in protected areas. While many of the households note some improvement in income following migration, many families and communities are burdened by extreme poverty, poor to nonexistent access to public education, and unusually high rates of maternal and infant mortality (Carr 2006). 


\section{Data and Methods}

The Demographic and Health Survey (DHS) data collected in 1998/99, by the Guatemalan Instituto Nacional de Estadistica and Measure/DHS+, Macro international, is used for this analysis (MSPAS 1999). The DHS is the largest ongoing survey in the world and is the primary source of data on population, health, and socio-economic indicators for developing world nations. The 1998/99 DHS is unique in that it is the first to incorporate an environmental survey module, thus allowing for analyses that explicitly link health and fertility outcomes to natural resource and environmental factors. This is key in a frontier context in which the population is overwhelmingly comprised of subsistence farm families (Grandia \& Schwartz 2001). The DHS data is invaluable for conducting research of this type among this high fertility and dynamic population. Not only do the DHS results provide extensive information regarding individual and family health and cultural norms, the large sample size provides a fantastic overview of large-scale trends and ultimately enables region-wide generalizability of the results. Moreover, the 1998/99 survey represents the first large-scale data collection of reproductive health information of inhabitants of the Petén region. Previously, this extremely impoverished population was excluded from surveys and was therefore un-represented in policy decisions based on large-scale analyses. Select descriptive variables and their sample sizes are presented in Table 3.

Guatemala national agriculture and population census data, compiled in 2002, compliment the DHS data. The Population Census contains information on more than 10 million Guatemalans (roughly the entire country), while the Agricultural Census is aggregated to the municipality level (12 municipalities in Petén) based on the response of surveyed farmers in each area (MSPAS 2002). Table 4 presents the variables from these censuses used in the analysis. Data from these censuses will be used to provide contextual level information to the quantitative analysis.

Analysis will be conducted using traditional generalized linear modeling (GLM) techniques where the response variable is assumed to follow a Poisson distribution. Results from this 
model were also compared with results from the negative binomial and multi-level regression (see appendix). The Poisson model was determined to provide the best fit to the data, however, and the results of this model are presented here.

\section{Results}

Two separate classes of models were constructed; one used municipality as the random effect while the other model incorporated the sampling cluster as the random effect. The clusters used are based on the sampling strategy of the data gathering and represent smaller geographic areas which are more like "neighborhoods" as compared to the municipality grouping. There were 77 clusters in the sample. The municipalities are much larger geographic areas which contain several clusters each (no clusters overlap regions). The region is geographically and politically divided into 12 distinct municipalities. Nesting individuals within their municipality or sampling cluster (as random effects) was not necessary to explain the variation in the response, and any inclusion of individual random effects did not sufficiently improve model fit to justify the inclusion of this more complicated modeling strategy. Therefore, the final models are fit as a generalized linear model with a log link to accommodate the count nature of the response variable. The dispersion parameter is nearly 1 for all models indicating that the mean/variance requirements of the Poisson model are met and therefore that the model is not overdispersed. Table 4 presents the significant variables and the model coefficients. Model 1 contains only the socio-demographic variables. Model 2 contains the household land use variables in addition to the socio-demographic variables and Model 3 updates Model 2 with the inclusion of municipality level variables. Significance was determined using the chi-squared tests where deviance values of the models were compared upon explanatory variable inclusion.

The significance of the socio-demographic variables in all three model specifications, supports classic theories of fertility determinants while also suggesting that the interplay between socio-economics, land use and fertility may be important. Maternal age is positively correlated with fertility where women older than 40 have the highest fertility. The significance of age, 
however, can also indicate an ideational cohort effect or a change in the ideals and values of younger women (perhaps favoring families with fewer children). In this analysis it is not possible to separate the impact of ideation or exposure for this particular variable - and therefore it is important to keep the complex nature of the variable in mind when reviewing the results. Maternal education and partner education are both negatively correlated with fertility. The differences between the lowest category of education and completion of primary or secondary school are larger than those for the partner. Patterns of significance differ for the education variables across models. The significance and magnitude of women's secondary education decreases when the land use variables are added while the significance and magnitude of the partner's education increases when additional variables are added. Ethnicity is not determined to be a significant predictor of fertility in this research, suggesting that language and cultural barriers are secondary to education (in this case a measure of economic status and current socio-economic and place-contigent conditions).

Television ownership is significant in Model 1 and women who live in households with a television are expected to have fewer children than their counterparts without televisions. Television ownership suggests the importance and intertwined nature of ideation and socioeconomic level on fertility outcomes. The prediction that families will have fewer children in the case that the household possesses a television could result from either the increase in socioeconomic status that permits for spending on a television or the exposure to gender, family, and possibly, family planning values that reflect the ideas of more developed areas of the country or of Latin America. As television ownership is no longer significant once the land use variables are included, Model 2, it is a reasonable assumption that ownership serves primarily as a measure of income rather than as a means to informally educate women and families about contraception and Western family-size values. Similarly, urban residence is significant only in the socio-demographic model. Perhaps unsurprisingly, upon inclusion of land use variables, area of residence is no longer significant. The change in significance of area of residence suggests that the variable serves as an indicator of child labor needs rather than access or exposure to family planning services. Finally, consistent with classic hypotheses, infant mortality remains 
a significant predictor in all three models of fertility.

The significance of the land use/labor variables highlights the complex nature of individual and household decisions to reproduce. Model 2 has a significantly reduced value of the Akaike Information Criterion (AIC) ${ }^{1}$ value as compared to Model 1, which supports the inclusion of land use variables with socio-demographic variables to evaluate fertility in Petén. Cattle ownership as hypothesized by Carr \& Pan (2007), Coomes et al. (2001) and others to have a negative effect on fertility as families invest resources in cattle as insurance in case of future needs (rather than investing in offspring). Also, as cattle are less labor intensive than food crops, fewer children are necessary to aid in farm work. In this case, however, cattle ownership is positively correlated with fertility. After closer study of the impact of slight increases in socio-economic status in extremely poor communities, cattle ownership measures a different aspect of socio-economic level. In this semi-frontier context cattle ownership facilitates an increase in births perhaps by motivating families to greater reproductive levels as the family has confidence of being able to meet the increased economic needs of a larger family. The positive, significant correlation between children and cattle ownership suggests that motivations of increased economic success are likely well founded, perhaps more children, who provide labor and expand the family's wealth, facilitate the investment in cattle. In this context initial increases in higher economic levels correspond to larger families. In related research larger families lead to increased economic standing of the family as laboring children can increase the household income (Cochrane, Kozel \& Alderman 1989). Contrary to the overarching negative relationship between socio-economic status and fertility, research has shown that at the very lowest socio-economic status levels, incremental increases in socio-economic status lead to increased fertility before the inexorable decline sets in.

Furthermore, when sons serve as labor the family is expected to have more children. This variable directly measures the economic benefit of children and supports the traditional theories. The variable indicating the sufficiency of household production, however, is not a significant

\footnotetext{
${ }^{1} \mathrm{~A}$ likelihood based measure of fit which adjusts for higher numbers of independent variables is included. A lower AIC represents an improved model over a model with a higher AIC.
} 
predictor of fertility. Finally, the fact that all of the municipal level variables, Model 3, were not statistically significant suggests that individual and household characteristics have a stronger impact on individual behavior.

\section{Discussion and Conclusion}

In this research we created a model of fertility determinants in Petén, Guatemala, a high fertility, largely rural area, with expansive (but quickly decreasing) forests. Among traditional socio-demographic variables, gender equity and ideation variables, variables measuring land use and children's labor were incorporated to determine if families deliberately strive to increase family size when agricultural labor needs are present.

Consistent with the fertility literature, increasing women's education can significantly decrease the number of births. As education continues to become more available, potentially facilitated by technology that enables remote learning, men's and women's education can expand and fertility in this area should eventually decline. As explained previously, the importance of men's education highlights the significance of the socio-economic level of the household. While expanding men's education is anticipated to continue to reduce fertility, an increase in economic opportunities should also reduce fertility.

Ethnicity was not a significant predictor of fertility in this context. This is surprising prima facie given the historic macro-level differentials in fertility and contraceptive use between the two ethnic groups and the persistence of social and economic marginalization among the nonSpanish speaking Indigenous population. However, this result is consistent with the growing body of literature that suggests that socio-economic fertility determinants trump cultural factors in explaining reproductive behavior. Over time, to the degree that socio-economic level increases, cultural differences may become more or less dominant but, at least at the onset of the fertility transition, economic factors appear to be playing a larger role in fertility differentials (Bryant 2007).

The implementation of land use and labor variables provides a unique opportunity to de- 
termine the impact of labor needs on fertility. This research introduces variables that have not been used in fertility analyses in Central America and explores the link between land use, socio-economic development, and reproductive health. While results are in some regards inconsistent with our initial hypothesis, the significance of these unorthodox variables underscores the importance of the link between population and the human-shaped environment. A classic view supporting the economic value of children posits that when children serve as labor, families will have more children. That theory is supported here by the positive correlation between the sons-as-labor variable and the concomitant level of fertility. Further building on the idea of children as an economic benefit is the hypothesis that when families invest in cattle they need less labor. They have also invested in their future, as cattle serve as an asset that can be sold if necessary. However, Petenero families have more children when they own cattle. An increase in children given the presence of cattle is inconsistent with traditional theories of the economic benefit of children. It does, however, support empirical findings suggesting that in such an inchoate stage of the fertility transition more wealth may translate to larger family size vis a vis a decrease in infant mortality. In Petén cattle provide a measure of old-age security and serve as a measure of wealth that may enable larger family size.

Fertility rates in Petén, Guatemala remain unusually high. The social and political turmoil that has characterized Guatemala's recent past have made headlines while little has been researched on the demographic determinants and implications of this sustained high fertility phenomenon. This analysis combined and applied theories of fertility and land use to help develop an understanding of fertility behavior in this underrepresented region of the world. Through the use of individual, household and municipality level factors, the findings contribute to enhancing scientific understanding of the impact of community/context factors on individual behaviors. Ultimately the findings underscore the importance of individual- and household-level factors and downplay the role of municipality-level factors in determining fertility. The results, therefore, encourage the implementation of individual- and household-level health and development policies. The findings also support a link between fertility and land use/labor. The final model contradicts a theory of rural fertility and land use through the positive correlation 
of fertility with cattle ownership. Reviewing the model results ensemble supports the notion that when children provide labor (as help on other farms or as labor on family farms), families have more children; presenting an important link between reproductive decisions and economic benefit. Most of the families in this region live in rural areas and the majority of respondents indicate that any household economic surplus is directed towards increasing livestock holdings rather than towards family/household costs. It is possible that increased family size actually augments household income (through the labor of the children) allowing families to invest in more cattle and improve their sense of financial security. Therefore, in the context where larger families lead to financial stability, we can anticipate fertility decline only when social mores and economic norms are challenged by external processes.

Results are limited by the cross-sectional nature of the data making it impossible to determine the causal factors of fertility change (possible in a longitudinal data setting), however, these results can indeed be used to begin to disentangle the impact on fertility of sociodemographic, economic and land-use variables as well as to begin to make hypotheses regarding their interaction. 
Table 1: 1998/99 Guatemalan Regional Total Fertility Rates

\begin{tabular}{cc}
\hline Region & TFR \\
\hline Metropolitan & 4.3 \\
North & 5.5 \\
Northeast & 5.4 \\
Southeast & 5.1 \\
Central & 5 \\
Southwest & 5.3 \\
Northwest & 6.2 \\
Petén & $\mathbf{6 . 8}$
\end{tabular}

Note: Calculated by Guatemalan 1999 ENSMI. Data from 1998/99 DHS. 
Table 2: Explanatory Variables

\begin{tabular}{lll} 
Category & Individual & Expected \\
\hline Socio-Demographic & Age & + \\
& Education & - \\
& Partner Education & - \\
& Ethnicity (Indigenou) & - \\
& Television Ownership (yes) & - \\
& Urban (yes) & + \\
& Infant/Child Mortality (yes) & - \\
\multirow{5}{*}{ Land Use and Labor } & Cattle Ownership (yes) & + \\
& Sons in Fields (yes) & - \\
& Production Sufficient (yes) & + \\
& Out-migration (domestic) & - \\
\hline & Percent Forested Land & \\
\hline
\end{tabular}


Table 3: Descriptive Statistics for Selected Variables from the 1998/99 DHS

\begin{tabular}{lcc}
\hline Variable & Percent & Sample Size \\
\hline Age & $26 \%$ & 1129 \\
$15-19$ & $28 \%$ & \\
$20-24$ & $25 \%$ & \\
$25-29$ & $23 \%$ & \\
$30-34$ & $23 \%$ & \\
$35-39$ & $9 \%$ & \\
$40-44$ & $7 \%$ & \\
$45-49$ & $34 \%$ & 1129 \\
Education (none) & $52 \%$ & \\
Primary & $14 \%$ & \\
Secondary and beyond & $36 \%$ & \\
Partner Education (none) & $51 \%$ & \\
Primary & $13 \%$ & 1129 \\
Secondary and beyond & $26 \%$ & 1127 \\
Indigenous & $29 \%$ & 592 \\
Television Ownership (yes) & $79 \%$ & 835 \\
Production Sufficient (yes) & $16 \%$ & 557 \\
Cattle Ownership (yes) & $43 \%$ & \\
Sons in Fields (yes) & &
\end{tabular}

Note: Author's calculations based on 1998/99 DHS data. 
Table 4: Poisson Regression Results Modeling Fertility in Petén, 1998/99

\begin{tabular}{|c|c|c|c|c|c|c|c|}
\hline & \multirow[b]{3}{*}{ Variable } & \multicolumn{6}{|c|}{ Poisson Estimates } \\
\hline & & \multicolumn{2}{|c|}{ Model 1} & \multicolumn{2}{|c|}{ Model 2 } & \multicolumn{2}{|c|}{ Model 3} \\
\hline & & Coefficient & Sig. & Coefficient & Sig. & Coefficient & Sig. \\
\hline \multirow[t]{21}{*}{ Socio-demographic } & Age (15-19) & & & & & & \\
\hline & $20-24$ & 0.809 & $* * *$ & 0.658 & $* * *$ & 0.657 & *** \\
\hline & $25-29$ & 1.289 & $* * *$ & 1.086 & *** & 1.090 & *** \\
\hline & $30-34$ & 1.517 & $* * *$ & 1.307 & *** & 1.308 & *** \\
\hline & $35-39$ & 1.658 & $* * *$ & 1.404 & $* * *$ & 1.404 & *** \\
\hline & $40-44$ & 1.834 & $* * *$ & 1.564 & *** & 1.568 & *** \\
\hline & $45-49$ & 1.800 & $* * *$ & 1.496 & *** & 1.506 & *** \\
\hline & Education (none) & & & & & & \\
\hline & Primary & -0.056 & & -0.068 & & -0.064 & \\
\hline & Secondary and beyond & -0.518 & $* * *$ & -0.443 & $*$ & -0.423 & $*$ \\
\hline & Partner Education (none) & & & & & & \\
\hline & Primary & -0.039 & & -0.024 & & -0.019 & \\
\hline & Secondary and beyond & -0.189 & * & -0.303 & * & -0.309 & ** \\
\hline & Ethnicity (Indigenous) & & & & & & \\
\hline & Ladino & 0.017 & & 0.009 & & 0.007 & \\
\hline & Television Ownership (no) & & & & & & \\
\hline & Yes & -0.130 & $* *$ & -0.092 & & -0.085 & \\
\hline & Urban (no) & & & & & & \\
\hline & Yes & -0.017 & * & -0.026 & & 0.011 & \\
\hline & Infant/Child Mortality (no) & & & & & & \\
\hline & Yes & 0.336 & $* * *$ & 0.318 & $* * *$ & 0.317 & $* * *$ \\
\hline \multirow[t]{6}{*}{ Land Use/Labor } & Cattle Ownership (no) & & & & & & \\
\hline & Yes & & & 0.131 & ** & 0.141 & ** \\
\hline & Sons Work in Fields (no) & & & & & & \\
\hline & Yes & & & 0.135 & ** & 0.135 & ** \\
\hline & Suff. Household Production (no) & & & & & & \\
\hline & Yes & & & -0.062 & & -0.055 & \\
\hline \multirow{3}{*}{ Municipality } & Outmigration & & & & & -0.080 & \\
\hline & Forested Land & & & & & -0.439 & \\
\hline & Number of Tractors per Farm & & & & & 0.566 & \\
\hline Degrees of Freedom & & 898 & & 519 & & 516 & \\
\hline Residual Deviance & & 755.6 & & 416.36 & & 413.73 & \\
\hline AIC & & 3528.9 & & 2176.5 & & 2179.9 & \\
\hline
\end{tabular}


Figure 1: Fertility in Guatemala 1998/99

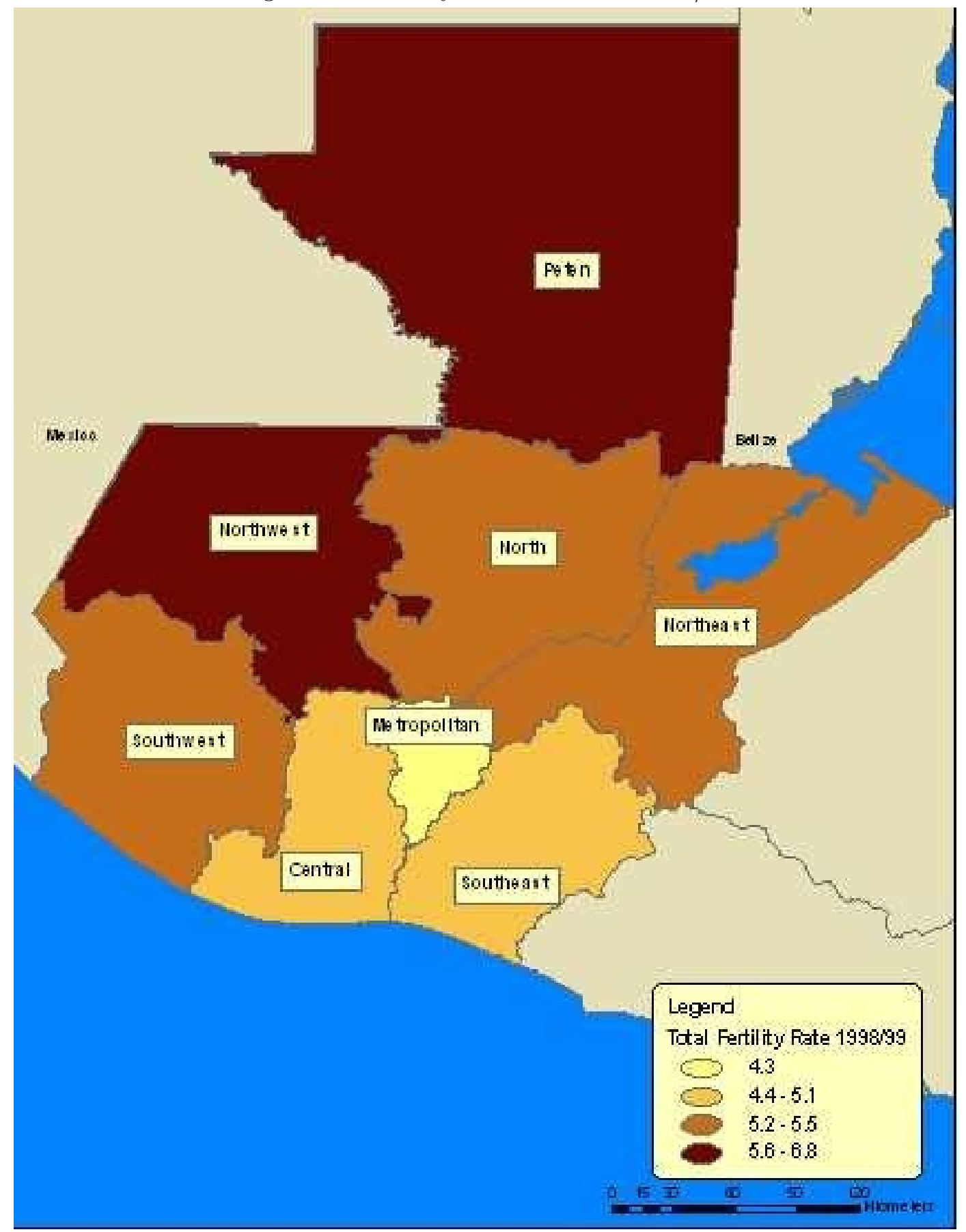

Note: Data come from 1998/99 DHS ENSMI. 


\section{References}

Bertrand, J., E. Seiber \& G. Escudero (2001), 'Contraceptive dynamics in Guatemala: 19781998', International Family Planning Perspectives 27(3), 112-118 + 136.

Bertrand, J., S. Guerra de Salazar, L. Mazariegos, V. Salanic, J. Rice \& C. Kolars Sow (1999), 'Promoting birthspacing among the Maya-Quiche of Guatemala', International Family Planning Perspectives 25(4), 160-167.

Binswanger, H. \& J. McIntire (1987), 'Behavioral and material determinants of production relations in land-abundant tropical agriculture', Economic Development and Cultural Change 36(1), 73-99.

Bongaarts, John (1978), 'A framework for analyzing the proximate determinants of fertility', Population and Development Review 4(1), 105-132.

Bryant, J. (2007), 'Theories of fertility decline and the evidence from development indicators', Population and Development Review 33(1), 101-127.

Cain, M. (1984), On the relationship between landholding and fertility, New York: New York Center for Policy Study.

Caldwell, J. C. \& P. Caldwell (1987), 'The cultural context of high fertility in sub-Saharan Africa', Population and Development Review 13(3), 409-437.

Carr, David (2006), 'A tale of two roads: population, poverty, and politics on the Guatemalan frontier', Geoforum 37(1), 94-103.

Carr, D.L. (2008), 'Migration and tropical deforestation: Why population matters', Progress in Human Geography 33(2).

Carr, D.L., W. Pan \& R.E. Bilsborrow (2006), 'Declining fertility on the frontier: The Ecuadorian Amazon', Population and Environment 28(1), 17-39. unpublished.

Chayanov, A.V. (1986), The theory of peasant economy, Madison: University of Wisconsin Press.

Clay, D. \& N.E. Johnson (1992), 'Size of the farm or size of the family: Which comes first?', Population Studies 42(3), 491-505.

Cleland, John \& Christopher Wilson (1987), 'Demand theories of the fertility transition: An iconoclastic view', Population Studies 41(1), 5-30.

Coale, Ansley J. (1973), 'The demographic transition', IUSSP Liege International Population Conference 1, 53-72.

Coale, Ansley J. \& Susan Cotts Watkins, eds (1986), The Decline of Fertility in Europe, Princeton University Press, Princeton. 
Cochrane, S. H., V. Kozel \& H. Alderman (1989), 'Household consequences of high fertility: the case of Pakistan', Presented at the Annual Meeting of the Population Association of America (PAA), Baltimore, Maryland.

Coomes, O., F. Grimad \& V. Diaz (n.d.), 'Peasant farm size and family size: A causality analysis from the Peruvian Amazon', Northeast Universities Development Consortium Conference (NEUDC), Boston University.

Davis, K. \& J. Blake (1956), 'Social structure and fertility: An analytic framework', Economic Development and Cultural Change 4(4), 211-235.

De Broe, Sofie \& Andrew Hinde (2006), 'Diversity in fertility patterns in Guatemala', Population, Space and Place 12, 435-459.

Easterlin, R.A. (1971), 'Does human fertility adjust to the environment?', American Economic Review 61, 399-407.

Entwisle, B., R.R. Rindfuss, D.K. Guilkey, A. Chamratrithirong, S.R. Curran \& Y. Sawangdee (1996), 'Community and contraceptive choice in rural Thailand: A case study of Nang Rong', Demography 33(1), 1-11.

Faraway, Julian (2006), Extending the Linear Model with R: generalized linear, mixed effects and non-parametric regression models, Chapman Hall.

Grandia, L. \& N. Schwartz (2001), Peten: Salud migracion, y recursos naturales, Technical report, Guatemala, Instituto Nacional de Estadistica.

Knodel, J. A., A. Chamratrithirong \& N. Debavalya (1987), Thailand's Reproductive Revolution: Rapid Fertility Decline in a Third-World Setting, University of Wisconsin Press.

Kohler, H., J. Behrman \& S. Watkins (2001), 'The density of social networks and fertility decisions: evidence from South Nyanza District, Kenya', Demography 38(1), 43-58.

Lee, R. (2001), International Encyclopedia of the Social and Behavioral Sciences, Vol. 3, Elsevier Science Ltd, chapter Externalities to childbearing.

Lee, R. \& K. Kramer (2002), 'Children's economic roles in the context of the Maya family life cycle: Cain, Caldwell, and Chayanov revisted', Population and Development Review 28(3), 475-499.

Lindstrom, D. P. (2003), 'Rural-urban migration and reproductive behavior in Guatemala', Population Research and Policy Review 22, 351-372.

Lindstrom, D. P. \& E. Munoz-Franco (2005), 'Migration and diffusion of modern contraceptive knowledge and use in rural Guatelama', Studies in Family Planning 36(4), 277-288.

Lovell, G. (1999), Land and Peace. Journeys of Fear: Refugee Return and National Transformation in Guatemala, McGill-Queen's University Press.

Martine, G. (1996), 'Brazil's fertility decline, 1965-95: a fresh look at key factors', Population and Development Review 22(1), 47-75. 
McCullagh, P. \& J.A. Nelder (1989), Generalized Linear Models, Chapman Hall, New York.

Montgomery, M.R. \& J.B. Casterline (1996), 'Social learning, social influence, and new models of fertility', Population and Development Review 22(Suppl), 151-75.

MSPAS (1999), Guatemala: Encuesta nacional de salud materno infantile, Technical report, Ministerio de Salud Publica y Asistencia Social (MSPAS), Instituto Nacional de Estadistica (INE), Demographic and Health Surveys (DHS), Calverton, MD, USA: Macro International.

MSPAS (2002), Guatemala: Encuesta nacional de salud materno infantile 2002 informe final, Technical report, Ministerio de Salud Publica y Asistencia Social (MSPAS), Instituto Nacional de Estadistica (INE), Centers for Disease Control (CDC), Gautemala City:MSPASINE-CDC.

Pebley, A., N. Goldman \& A. Robles (2005), 'Isolation, integration, and ethnic boundaries in rural Guatemala', The Sociological Quarterly 46, 213-236.

Pebley, A.R., N. Goldman \& G. Rodriguez (1996), 'Prenatal and delivery care and childhood immunization in Guatemala: do family and community matter?', Demography 33(2), 23147.

Raftery, Adrian E., Steven M. Lewis \& Akbar Aghajanian (1995), 'Demand or ideation? evidence from the Iranian marital fertility decline', Demography 32(2), 159-182.

Rodriguez, German \& Noreen Goldman (2001), 'Improved estimation procedures for multilevel models with binary response: a case study', Journal of Royal Statistical Society. Series A 164(2), 339-355.

Santiso-Galvez, Roberto \& Jane T. Bertrand (2004), 'The delayed contraceptive revolution in Guatemala', Human Organization 63(1), 57-67.

Seiber, E. \& J. Bertrand (2002), 'Access as a factor in differential contraceptive use between Mayans and ladinos in Guatemala', Health Policy and Planning 17(2), 167-177.

Stokes, C.S., W.A. Schutjer \& R.A. Bulatao (1986), 'Is the relationship between landholding and fertility spurious? a response to Cain', Population Studies 40(2), 305-311. 


\section{Notes}

Generalized linear models build on the standard regression technique in two different ways. First, the non-normal nature of the dependent variable (total children ever born) requires the use of a link function and therefore transforms a linear regression approach to a generalized linear approach. In the context of total children ever born, the count of births is discrete and therefore violates the assumptions contained of the Gaussian distribution (McCullagh \& Nelder 1989). Instead, the Poisson distribution is commonly applied to variables that represent counts of events. To develop a regression model in the case where the dependent variable is assumed to follow a Poisson distribution, a log link is used. Equation 1 shows the linear combination of explanatory variables and estimated coefficients on the response, $\eta$. Since I am using the Poisson distribution to model the response then I introduce a link function, $g(\mu)=\eta$ where $\mu$ is equal to the expected value of the response and, consistent with common application, $\eta=\log (\mu)($ McCullagh \& Nelder 1989).

$$
\eta=\beta_{0}+\beta_{1} x_{1}+\ldots+\beta_{j} x_{j}
$$

In response to the limitations (mean equal to variance) of the Poisson distribution which can cause the model to be over/under - dispersed, the negative-binomial distribution is a viable alternative distribution. The negative-binomial distribution is a more flexible distribution allowing the variance term to vary with each independent observation. In fact, the construction of the negative binomial distribution follows as a hierarchical or two-level distribution where the expected value of the response follows a Poisson distribution but the variance term for each observation follows a gamma distribution. For rate $\lambda$, the mean and variance of the distribution, $\mathrm{E} \lambda=\mu$ (equal to the expected value of the response) while the $\operatorname{var}(\lambda)=\mu / \theta$ (Faraway 2006). Assuming that the dependent variable follows the negative-binomial distribution allows the variance term to vary over individuals and removes the restriction of equality of the mean and variance. In this paper both distributions, the Poisson and negative-binomial, will be used for modeling the phenomena of interest and will be briefly compared and evaluated to determine 
the best modeling scheme.

The generalized linear mixed model approach, also applied to the data, is distinct from classical generalized linear regression, as it incorporates random effects into the model. Random effects are used to compare a sample of items taken from the population of items. In this case, I use municipality as a random effect which effectively permits an adjustment for the possibility that there may be clustering at the municipality level resulting in a violation of the independence of observations requirement for generalized linear modeling. Without incorporating this into the model, the observations cannot be regarded as independent and the resulting standard errors, and in some cases point estimates, can be incorrect (Rodriguez \& Goldman 2001). By fitting a random intercept model, the error is partitioned into two components, one due to individual variation unexplained by the independent variables and one attributable to the municipality level. 